receiving and recording system, with fifty-two channels, and data are continuously recorded on $16 \mathrm{~mm}$ film, punched on computer cards and then fed to a computer which prints out any desired information about the animal and its movements.

Perhaps equally complex is the system described by Dr J. J. Craighead (Montana Cooperative Wildlife $\mathrm{Re}$ search Unit) to record environmental and physiological data from the winter den of a hibernating black bear. The system was made available by NASA, and involved an IRLS unmanned data station with twenty-eight channels. In what he called a feasibility experiment Dr Craighead and his colleagues monitored temperature and light intensity with sensors placed at various points in and around the bear's den. Signals from these sensors were interrogated at 12-hour intervals by the IRLS platform and were transmitted to Fairbanks tracking station. From Fairbanks, data were sent by telephone line and microwave link to the Nimbus data processing centre at NASA's Goddard Space Flight Center near Washington DC, where the data were processed, printed out by computer and sent to the experimenter. The system used was probably far more complex than was needed in this particular case but, as $\mathrm{Dr}$ Craighead pointed out, it would have advantages in work on animals in remote areas.

Some of the local work reported involved straightforward radio tracking of medium-sized and large mammals; for example, studies have been made by Dr P. P. de Moor and Dr F. E. Steffens (CSIR) on vervet monkeys, by Mr P. M. Hitchins (Natal Parks Board) on black rhino, by $\mathrm{Mr} \mathrm{N}$. Owen-Smith (Natal Parks Board) on white rhino, and by Dr D. H. M. Cumming (National Parks, Rhodesia) on warthog. There were also some reports on physiological monitoring, for example $\mathrm{Dr}$ E. D. Smith (CSIR) on activity and heart action in sharks, Dr G. D. Brown (CSIRO, Australia) on temperature, respiration rate and activity in sheep and kangaroos, and Dr A. M. Harthoorn (Transvaal Nature Conservation) on temperature in various wild ungulates.

A discussion panel under Professor $\mathrm{J}$. Meester (University of Pretoria) came up with two recommendations emphasizing the important part that the CSIR has played, and is expected to play, in biotelemetry: that a committee be set up, under the aegis of the CSIR, to coordinate future developments in bioengineering; and that a central workshop be set up within the CSIR, where further research and development can be undertaken, and which can lease equipment to research workers for specific projects.

\section{Chimp Language}

from our Animal Behaviour Correspondent

APPARENT differences between animal communication and human language continue to dwindle as more and more is discovered of the capabilities of animals. It has often been maintained that one of the distinctive features of human language is its creativity, humans, unlike other animals, possessing the ability to invent new signals or to put existing ones into new sequences. But the remarkable success of $R$. A. and B. T. Gardner in teaching sign language to a young chimpanzee named Washoe showed that this distinction is not always valid, because Washoe showed definite evidence of creativity in just this sense. (A preliminary account of the Gardners' work is to be found in Science, 165, 664 ; 1969, but Washoe has progressed considerably since then.)

Another distinguishing feature was thought to lie in what animals communicated, the idea being that animals conveyed no more than their current mood or motivation and could not transmit information about their external environment. Studies on a number of different animals have shown that this is not the case and E. W. Menzel (Folia Primat, 15, 220; 1971) has recently provided more evidence that animals can communicate about their environment.

Menzel experimented with a group of eight young chimpanzees which were all well known to one another. Out of sight of the rest of the group, one of them, called the leader, was shown the whereabouts of a hidden pile of food but was not allowed to eat it. The leader was then reunited with its companions and the whole group was released together into the test area. As the leader headed for the food, the others followed or even ran ahead of their leader.

If the leader had been shown not food but a plastic toy or other fear-inducing stimulus, the behaviour of the others was quite different (more cautious) even before the toy was visible to them and even if the toy had been removed in the meantime. In trials where there were two leaders and one had been shown fruit (a highly preferred food) and the other had been shown vegetables (less preferred) the whole group tended to go straight to the fruit, implying that there had been some sort of "pooling of information").

It is interesting that in most cases there was little obvious signalling between the animals, that is, no conspicuous calls or gestures. Communication between these chimpanzees was thus accomplished through some very subtle aspect of their behaviour.

\title{
Mechanism of Kasugamycin Resistance
}

LAST September in Nature New Biology (233, 12; 1971) Helser, Davies and Dahlberg reported the striking discovery that the resistance of Escherichia coli to the antibiotic kasugamycin stems from a change in the 16S RNA moiety of $30 \mathrm{~S}$ ribosomal subunits and not from a mutation resulting in a change in a ribosomal protein. Resistance to streptomycin and to several other antibiotics, of course, results from a change to ribosomal proteins. Following up this discovery, important not least because it at last provides a handle on the question of the role of ribosomal RNA (ibid., page 1), Helser, Davies and Dahlberg have now, as they report next Wednesday in Nature New Biology (January 5), determined the function of the kasugamycin A locus of the $E$. coli chromosome, the locus which controls whether or not a cell is resistant to the antibiotic.

Knowing that the $16 \mathrm{~S}$ ribosomal RNA from resistant strains of $E$. coli lacks the dimethyl groups which are normally present on two adjacent adenine residues near the $3^{\prime}$ terminus of this molecule, Helser et al. set about trying to prove that the kasugamycin $\mathrm{A}$ locus specifies a specific RNA methylase. They found that extracts of wild type E. coli contain a methylase activity, not present in identical extracts of resistant cells, which, although it will not methylate naked 16S RNA from any source, will methylate the $16 \mathrm{~S}$ RNA moiety of $21 \mathrm{~S}$ ribonucleoprotein cores derived from the undermethylated $30 S$ ribosomal subunits of resistant cells. Similar $21 \mathrm{~S}$ cores from wild type $30 \mathrm{~S}$ ribosomes are not, however, methylated.

To prove that it is the RNA rather than the protein of the cores that is being methylated and to prove that the methylation is specific, Helser et al. made fingerprint analyses of the resistant $21 \mathrm{~S}$ cores which had been methylated in vitro. Sure enough the methyl groups had been added in vitro to the two adenine residues near the $3^{\prime}$ terminus. Moreover, they have been able to show that $30 \mathrm{~S}$ ribosomes reconstructed in the test tube from ribosomal proteins and cores from resistant ribosomes methylated in vitro are active in protein synthesis and are sensitive, not resistant, to kasugamycin. It seems, therefore, that the kasugamycin A locus is the structural gene for a specific methylase and a mutation in this gene which inactivates this enzyme confers resistance to the drug. 